\title{
GENETIC VARIATION IN A CONTINUOUSLY BREEDING POPULATION OF DANAUS PLEXIPPUS L. (LEPIDOPTERA: NYMPHALIDAE)
}

\author{
J. M. HUGHES* AND M. P. ZALUCKI† \\ * School of Australian Environmental Studies, Griffith University, Nathan Queensland 4111. \\ Australia; † Department of Entomology. University of Queensland, St Lucia, Queensland \\ 4067, Australia
}

Received 28.vi.83

\section{SUMMARY}

\begin{abstract}
Variation at 4 genetic loci ( $\mathrm{Pgm}$; Me; Idh; Hbdh) was studied in a population of monarchs (Danaus plexippus L.) not subject to migration to overwintering sites. Adult insects were sampled from 18 milkweed patches in 5 widely spaced locations in south-east Queensland (Australia). Genetic differentiation between sub-populations (patches) was high $\left(F_{S T}=0.032\right)$. For 2 loci (Me and Idh) both males and females showed significant differentiation between patches. Idh showed a significant cline with latitude in males only and Me showed no apparent geographic pattern in either sex. Both loci showed significant differences in gene frequencies between sexes. Possible mechanisms for maintaining these differences are discussed.
\end{abstract}

\section{INTRODUCTION}

In a study of the genetic structure of North American summer populations of the monarch butterfiy, Danaus plexippus L., Eanes and Koehn (1978) found low spatial variation in allele frequencies. The local variation that does occur is obviated in the fall. This Eanes and Koehn (1978) attribute to the distinctive population structure of monarchs, viz., summer breeding over much of North America, migration to Mexico and overwintering in autumn and winter, followed by spring migration back to summer breeding grounds (Urquhart 1960). The annual migration effectively mixes the population and removes any local differentiation.

The monarch was introduced into Australia around 1870 and has established a pattern of annual breeding, range expansion and contraction. Throughout coastal Queensland the monarch breeds year round (Smithers 1977). Since there is little seasonal mixing, we expect that monarchs will exhibit significant local genetic variation. In this paper we test this hypothesis by investigating the genetic structure of monarchs in south-east Queensland.

\section{MATERIALS AND METHODS}

Five widely spaced localities were chosen in south-east Queensland (fig. 1). Within each locality adult $D$. plexippus were netted from a number of milkweed (Asclepias fruticosa L.) patches (18 in all). At each patch we attempted to sample at least 25 butterflies. Specimens were brought back live in envelopes and frozen until electrophoresis could be carried out. Brief descriptive notes on the size of the patch and the condition and density of the plants were taken at each site. 
Each butterfly was sexed and the length of the right forewing measured to the nearest $\mathrm{mm}$. Wings were removed and bodies were homogenised in $5 \mathrm{ml}$ of phosphate buffer $(0 \cdot 1 \mathrm{M}$ Tris EDTA, $2 \mathrm{mg} / 1 \mathrm{NADP}$, adjusted to $\mathrm{pH}$ $6 \cdot 2$ using conc. $\mathrm{HCl}$ ). They were then spun at $10,000 \mathrm{rpm}$ for 20 minutes below $4^{\circ} \mathrm{C}$ in a Sorvall RC5B centrifuge. The supernatant was decanted into vials and stored at $-20^{\circ} \mathrm{C}$ until used.

Electrophoresis was performed on cellulose acetate plates (Titan III Helena Laboratories). Four polymorphic enzyme loci were examined. For Phosphoglucomutase (Pgm), Isocitrate dehydrogenase (Idh) and Malic enzyme (Me), $0.1 \mathrm{M}$ Tris glycine $p \mathrm{H} 8.5$ was used as the electrode buffer and for Hydroxybutyrate dehydrogenase (Hbdh), $0 \cdot 1 \mathrm{M}$ Tris citrate $p \mathrm{H} 7 \cdot 6$ was used.

To facilitate comparisons with the North American work, $F_{S T}$ statistics (standardised variances) were calculated for the common alleles (Eanes and Koehn 1978). The standardised variance provides a measure of between population differentiation.

\section{RESULTS}

Of the four loci examined, Pgm had three alleles. The other three each had two. $F_{S T}$ 's were calculated for each allele in Pgm, but only for the most common allele in the remaining three loci. Table 1 gives the value of $F_{S T}$, mean allele frequency $(\bar{p})$ and range of allele frequency $\left(p_{i}\right)$ for each allele. Four of the six alleles had highly significant $(p<0.005) F_{S T}$ values, indicating high genetic differentiation between sub-populations (milkweed patches). The mean $F_{S T}$ was $0 \cdot 032$.

TABLE 1

Mean sample size per collection $(\bar{n})$, mean frequency $(\bar{p})$, range and standardised variances $\left(F_{S T}\right)$ for the six common alleles

\begin{tabular}{lcccc}
\hline Allele & $\bar{n}$ & $\bar{p}$ & Range of $p_{i}$ & $F_{S T}$ \\
\hline Hbdh-S & 21 & 0.77 & $0.62-0.89$ & 0.017 \\
Idh-S & 24 & 0.89 & $0.71-1.00$ & $0.048^{* * *}$ \\
Me-F & 24 & 0.80 & $0.54-0.93$ & $0.093^{* * *}$ \\
Pgm-F & 14 & 0.40 & $0.14-0.68$ & $0.044^{* * *}$ \\
Pgm-M & 14 & 0.28 & $0.09-0.64$ & $0.032^{* *}$ \\
Pgm-S & 14 & 0.32 & $0.13-0.60$ & 0.022 \\
& & & \multicolumn{2}{c}{$\bar{F}_{S T}=0.032$} \\
\hline
\end{tabular}

${ }^{* *} p<0 \cdot 025$.

$* * * p<0.005$.

$F_{S T}$ values were calculated within each locality (table 2) and all alleles showed some variation in frequency between milkweed patch sites. This high "within locality" variation prevented pooling of sites for "between locality" comparisons. This variation could have been caused by gene frequency differences between sexes and/or size classes which were pooled to increase sample sizes. Males were significantly larger than females $(p<$ $0 \cdot 005$ ) and there were significant size differences between sites (males and females combined, $p<0 \cdot 005$ ). The latter was mainly due to male intersite differences (table 3 ). Sex ratios also differed significantly between sites 
TABLE 2

$F_{S T}$ values indicating amount of variation within each locality. (See fig. 1 for locations.)

\begin{tabular}{lcllll}
\hline Allele & Beaudesert & Beenleigh & Mt Crosby & Dayboro & Kenilworth \\
\hline Pgm-F & 0.0100 & 0.0255 & $0.0731^{* * *}$ & 0.0112 & 0.0110 \\
Pgm-M & 0.0160 & 0.0012 & 0.0435 & 0.0085 & 0.0062 \\
Pgm-S & 0.0071 & $0.0805^{* * *}$ & 0.0212 & 0.0180 & 0.0064 \\
Hbdh-S & 0.0048 & 0.0011 & $0.0268^{*}$ & $0.0015^{*}$ & $0.0268^{*}$ \\
Idh-S & 0.0010 & 0.0216 & $0.0276^{* *}$ & 0.0070 & $0.0725^{* * *}$ \\
Me-F & $0.0228^{*}$ & 0.0015 & 0.0075 & $0.0676^{* * *}$ & $0.0807^{* *}$ \\
\hline
\end{tabular}

${ }^{*} p<0.05$.

$* * p<0.025$

${ }^{* * *} p<0.005$.

$\left(\chi_{17}^{2}=34 \cdot 86, p<0 \cdot 01\right)$. For these reasons we analysed gene frequencies on the basis of sex and size.

Table 4 shows results of comparisons between sexes and size classes for each locus. There were no differences in allele frequencies between size classes, but there were significant differences between sexes for three loci: Me, Idh and Pgm (table 4).

TABLE 3

Results from Anovas showing size differences with site and sex

\begin{tabular}{lrrrrrr}
\hline \multicolumn{1}{c}{ Effect } & \multicolumn{2}{c}{ Male and female } & \multicolumn{2}{c}{ Male } & \multicolumn{2}{c}{ Female } \\
\hline \multicolumn{1}{c}{ of } & df & \multicolumn{1}{c}{$F$} & df & $F$ & df & $F$ \\
Site & 17 & $2 \cdot 35^{* * *}$ & 17 & $1 \cdot 802^{*}$ & 17 & $1 \cdot 134^{\text {Ns }}$ \\
Sex & 1 & $9 \cdot 43^{* * *}$ & & & & \\
Site $\times$ Sex & 17 & $0.63^{\text {Ns }}$ & & & & \\
\hline
\end{tabular}

$* p<0.05$.

$* * * p<0.005$.

NS $=$ Not significant

TABLE 4

Comparisons of frequencies $(f)$ between butterfly sex and size categories for each enzyme

\begin{tabular}{lcccccc}
\hline & & & Hbdh & Me & Idh & Pgm \\
\hline Males & $f \times$ size & $\chi^{2}$ & $4 \cdot 252$ & $6 \cdot 826$ & 5.676 & 16.444 \\
& & $\mathrm{df}$ & 6 & 6 & 6 & 15 \\
Females & $f \times$ size & $\chi^{2}$ & 6.012 & $2 \cdot 823$ & 4.825 & $10 \cdot 569$ \\
& & $\mathrm{df}$ & 4 & 6 & 6 & 15 \\
Total & $f \times$ sex & $\chi^{2}$ & $2 \cdot 244$ & $83.089^{* * *}$ & $22 \cdot 263^{* * *}$ & $15 \cdot 490^{* * *}$ \\
& & $\mathrm{df}$ & 1 & 1 & 1 & 2 \\
\hline
\end{tabular}

${ }^{* * *} p<0 \cdot 005$.

Me and Idh were further analysed for site differences within sexes. Pgm was excluded due to very small sample sizes. The high $F_{S T}$ values recorded (table 1) were not due to differences in sex ratios between sites as both males and females showed significant differentiation between sites (Me: $F_{S T}=0.0182, p<0.025$ for males; $F_{S T}=0.0785, p<0.01$ for females; Idh: 
$F_{S T}=0.0512, p<0.01$ for males; $F_{S T}=0.060, p<0.01$ for females). For malic enzyme, in all patches except one the frequency of the fast allele in males was less than in females (fig. 1), but there was no geographic pattern in either sex. On the other hand, Idh showed a distinct north-south cline in males. The fast allele becomes more common as one moves north (fig. 2). The correlation between frequency of the fast allele and latitude was significant in males $(r=0.57, p<0.025)$ but not in females $(r=0.26$, $p>0.05)$.

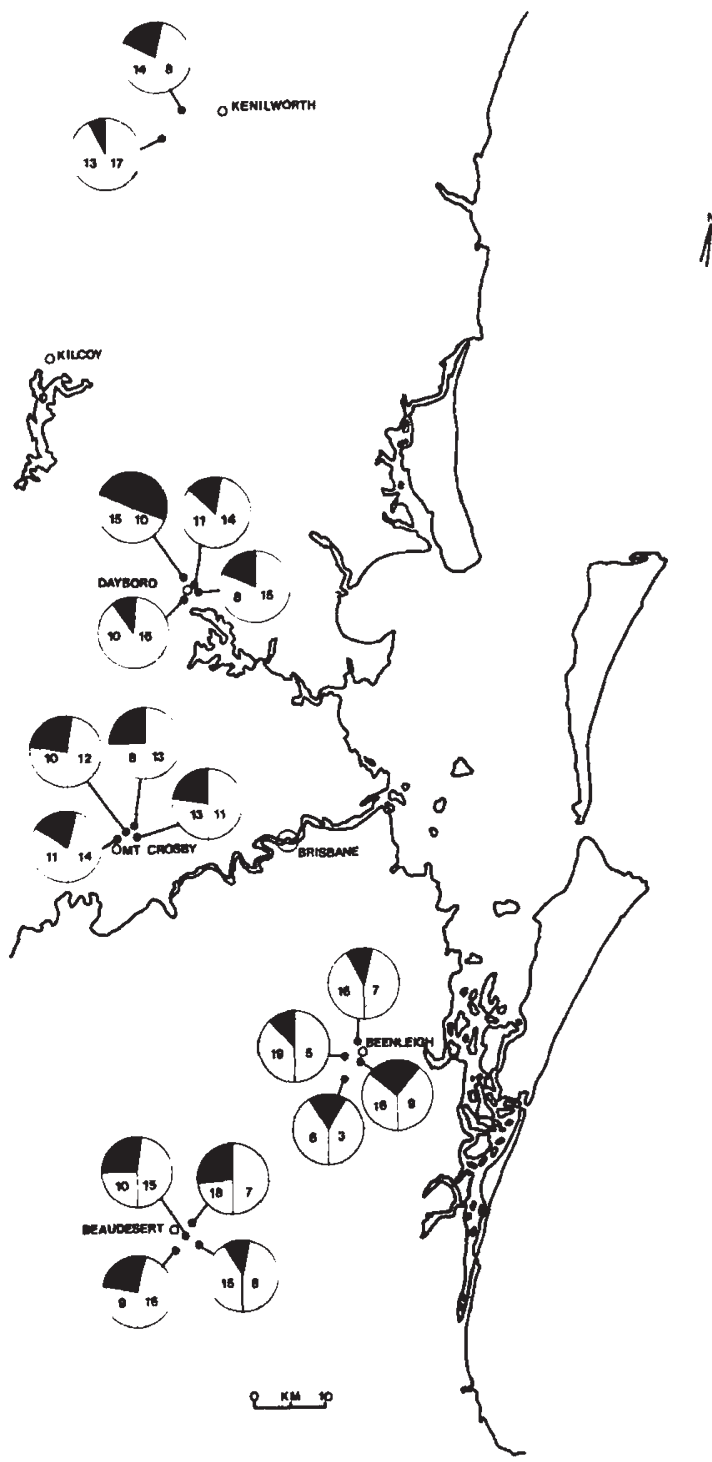

FIG. 1. Frequencies of Me in south east Queensland. The blackened areas of the pie diagrams represent $\mathrm{Me}^{\mathrm{s}}$. Males are on the left and females are on the right. Numbers inside semi-circles represent sample sizes. 


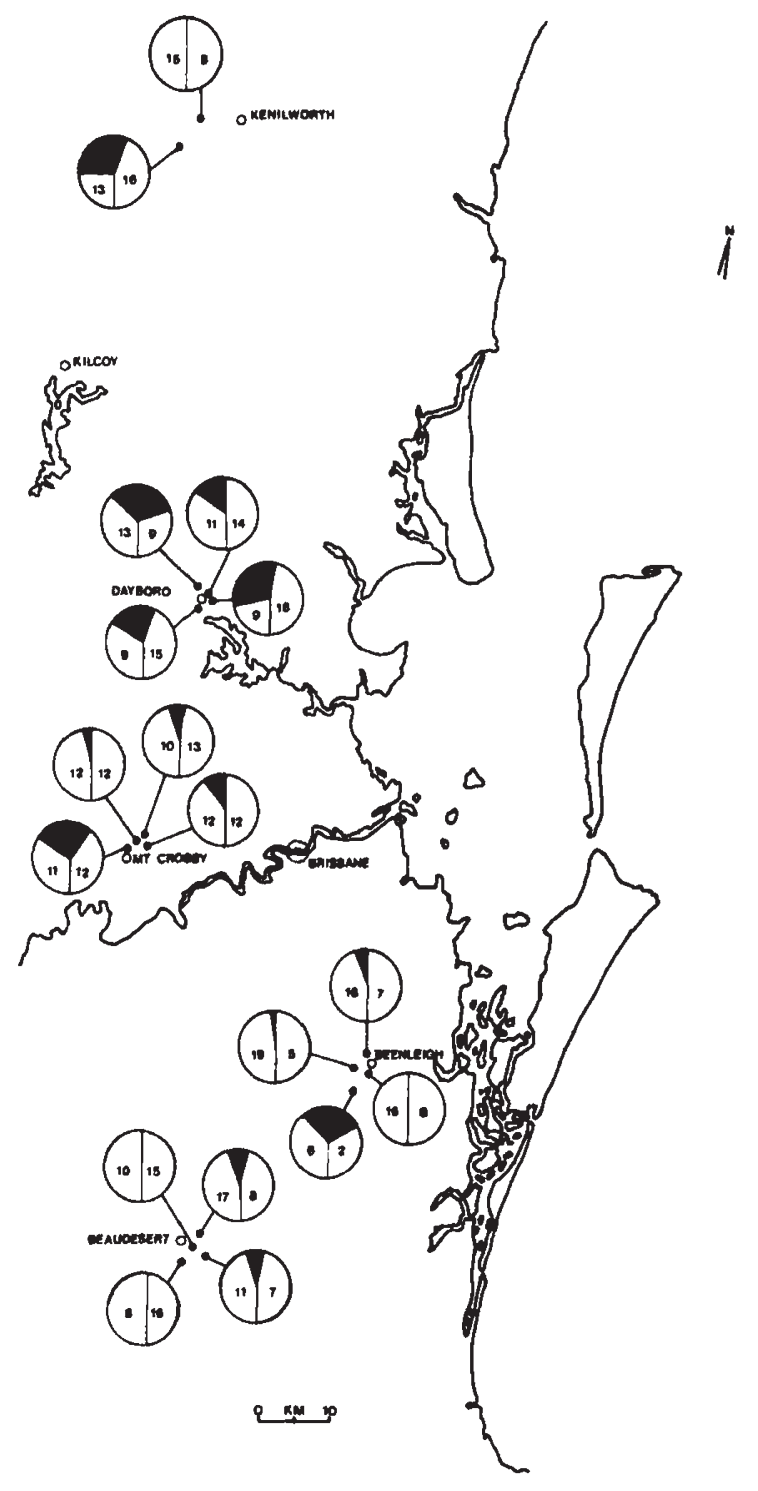

FIG. 2. Frequencies of Idh in south east Queensland. The blackened areas of the pie diagrams represent $\mathrm{Idh}^{F}$. Males are on the left and females are on the right. Numbers inside semi-circles represent sample sizes.

\section{Discussion}

As suggested earlier from a comparison of Monarch population structure between North America and south-east Queensland, relatively higher levels of local genetic differentiation would be expected in south-east Queensland. The mean $F_{S T}$ value of 0.032 was over three times that of 0.009 reported by Eanes and Koehn (1978) for the U.S.A. summer Monarch population. 
This value lies between those of Pieris rapae of 0.014 (Eanes and Koehn 1978), which is vagile and Euphydryas chalcedona of 0.09 , which is sedentary (McKechnie et al., 1975). Vagility plays an important part in differentiation between populations of a species (Barrowclough 1980; Winans 1980).

Inter-locality distances in the present study were much smaller (see figure 1) than those in the American study, where butterflies were sampled from twelve different states (Eanes and Koehn 1978). The fact that the $F_{S T}$ is still three times greater suggests much higher inter-population variation in south-east Queensland. As monarchs can move quite large distances, it seems unlikely that the differentiation observed here is due solely to isolation by distance, especially as much of the variation occurs between sites within localities (table 2).

Some mechanism, other than low gene flow, must be operating to maintain differences in gene frequencies between sites. The possible mechanisms are: natural selection on either adults or larvae, founder effect or selection by adults of particular patch types. The first suggestion seems unlikely because adults constantly move between patches and although selection may favour certain larval or adult genotypes within a patch, the adults sampled in a particular patch have mostly come from outside (Zalucki and Kitching, in review). Thus, selection effects are unlikely to be observed in single patches because the population is only part of a much larger population that moves through many patches. The founder effect also seems unlikely to affect gene frequencies, because the number of residents in a patch is small relative to the number of temporary visitors (Zalucki and Kitching, in review). Finally, adults may select different patch types, depending on their genotype. For example, adults with $\mathrm{Me}^{F} \mathrm{Me}^{F}$ genotype may select patches consisting of younger plants, whereas $\mathrm{Me}^{s} \mathrm{Me}^{s}$ individuals may choose older patches. Such mechanism could explain the type of frequency differences observed here. However, relating genotype to behaviour was beyond the scope of this study.

It is interesting that all three loci which show significant differentiation between sites also exhibit gene frequency differences between sexes. Eanes and Koehn (1978) also mentioned differences in gene frequencies between sexes at two different loci in monarch populations in U.S.A., but they offered no explanation for the phenomenon.

The differences observed in this study could result from different selection pressures on the two sexes. However, at mating, frequencies would be returned to roughly equal, therefore the differences observed at any one time would be the result of selection for only one generation. This means selection would have to be heavy to give the observed sex differences. As little is known of how the functions of the three enzymes may differ between the two sexes, a precise explanation of such a mechanism is not possible.

Another possible explanation for the observed sex differences is that males and females may differ in the way that their behaviour is influenced by their genotype. For example, $\mathrm{Me}^{F} \mathrm{Me}^{F}$ females may tend to spend long periods in patches, whereas $\mathrm{Me}^{F} \mathrm{Me}^{F}$ males may spend much of their time flying between patches. Because we sampled only patches, our results would be biased towards low frequencies of $\mathrm{Me}^{F} \mathrm{Me}^{F}$ in males.

Finally, the sex differences could be due to sex-linkage. However, these loci are definitely not sex-linked, because heterozygotes were recorded from both heterogametic (females) and homogametic (males) sexes. This would 
not be true for the heterogametic sex, if sex-linkage was involved because only a single copy of the gene would be present.

As well as significant sex differences at individual sites, at the Idh locus, we also observed a difference between sexes in the effect of latitude. In males, there was an obvious north-south cline, whereas in females there was no such relationship. Ford (1975) reported a similar situation in Maniola jurtina, where females varied significantly in the frequency of particular wing spot patterns between areas whereas males showed little change. (See also Pearse and Murray, 1982.) Handford (1973) examined esterases in Maniola jurtina and found large variations in frequencies at 2 loci in females. However, males were monomorphic. This situation is not quite analogous to the one described in this study, as the variaton in $M$. jurtina appears to be limited to females. In this study all morphs are found in both sexes. Only their frequencies differ. Neither of the above authors offered any explanation for these phenomena, other than to suggest that natural selection may affect the two sexes differently.

One possibility is that one sex moves more than the other, so that if there is a general north-south cline (due to selection), but more mixing occurs in one sex, then we would expect a mosaic in one sex and a cline in the other.

Acknowledgements. The authors with to thank Dr W. Boughton; Chairman of the School of Australian Environmental Studies, Griffith University; and Dr G. H. S. Hooper; Entomology Department, University of Queensland; for providing facilities for this study. Our thanks also to Peter Mather for grinding the samples, Susan Rea for drawing the figures and Drs J. Redfield and $\mathbf{R}$. Drew for reading an earlier version of the manuscript. This reasearch was supported by an Ian Potter Foundation grant.

\section{REFERENCES}

BARROWCLOUGH, G. F. 1980. Gene flow, effective population sizes, and genetic variance components in birds. Evolution, 34, 789-798.

EANES, W. F. AND KOEHN, R. K. 1978. An analysis of genetic structure in the monarch butterfly, Danaus plexippus L. Evolution, 32, 784-797.

FORD, E. B. 1975. Ecological Genetics. Chapman and Hall, London.

HANDFORD, P. T. 1973. Patterns of variation in a number of genetic systems in Maniola jurtina: the boundary region. Proc. Roy. Soc. Lond. B., 183, 165-284.

MCKECHNIE, S. W., EHRLICH, P. R. AND WHITE, R. R. 1975. Population genetics of Euphydryas butterflies. I. Genetic variation and the neutrality hypothesis. Genetics, 81, 571-594.

PEARSE, F. K. AND MURRAY, N. D. 1982. Sex and variability in the common brown butterfly Heteronympha merope merope (Lepidoptera: Satyrinae) Evolution, 36, 1251-1264.

SMITHERS, C. N. 1977. Seasonal distribution and breeding status of Danaus plexippus in Australia. J. Aust. Ent. Soc., 16, 175-184.

URQUHART F. A. 1960. The Monarch Butterfly. Univ. Toronto Press.

WINANS, G. A. 1980. Geographic variation in the milkfish Chanos chanos. I. Biochemical evidence. Evolution, 34, 558-574.

ZALUCKI, M. P. AND KITCHING, R. L. The dynamics of adult Danaus plexippus L. within patches of its food plant, Asclepias spp. Oecologia (in review). 